\title{
Comparison of respiratory tract congestion caused by exercise rowers' national team in the Islamic Republic of
} Iran

\author{
Yaghoub Mehri ALVAR 1, Majid KASHEF ${ }^{2}$, Alireza RAMEZANI ${ }^{3}$, \\ Naser HEIDARI ${ }^{4}$, Rasoul MOHAMADI ${ }^{5}$ \\ ${ }^{1}$ Department of Physical Education, Shahid Rajaee Teacher Training University, Tehran, Iran. \\ ${ }^{5}$ Department of Physical Education, Tehran center Branch, Islamic Azad University, Tehran, Iran. \\ Address Correspondence to N. Heidari, e-mail: naserheidari1987@gmail.com
}

\begin{abstract}
Any disorders of the respiratory system caused a decrease in overall functioning of the body and disturb the body's oxygen supply system. Regular physical activity can improve the function of the respiratory system. On the other hand, physical activity has been considered as a cause of bronchospasm and athletes in training and competition needs to put together the upper respiratory tract congestion, reduces the capacity of athletic activities. The aim of this study was to investigate the respiratory tract congestion is caused by the exercise of rowing national team. To study investigating 20 cases of rowers rowing and kayak national team of Iran (height: $182 \pm 4.2$, Weight: $80.04 \pm 5.6 \%$ Body fat $11 / 3 \pm 1.5$, VO2max: $62.2 \pm 2.4$ ) at least 5 years as a professional sport, and they were selected purposefully. In this study, the test boat was a $2000 \mathrm{~m}$ ergometer test. Before the activity, baseline spirometers test was performed, and again immediately after exercise, 5 and 30 minutes after exercise testing, spirometers was performed. The results show that the changes in respiratory parameters between these two disciplines, there is no significant difference and the results showed that all indicators showed significant changes in kayak ( $p<0.05$ ), but in rowing only significant change to create a variable force vital capacity, no sign of exercise-induced asthma percentage change in exercise does not show. Exercise can affect the respiratory parameters and Asthma intensity physical exercise is most affected. Higher or lower aerobic fitness athletes have exercise-induced asthma.
\end{abstract}

Keywords: Asthma, pulmonary ventilation, respiratory index, rowing.

\section{INTRODUCTION}

Respiratory system is one of the vital systems of body that is responsible for the evaluation of needed daily gases, activities and survival of human. Statistics show that dysfunction in cardiovascular tract and respiratory function is associated with increased mortality (5). In the meantime spirometry tests are effective methods to evaluate pulmonary function of healthy individuals, patients and athletes. This clinical test evaluates the magnitude of lung damage and level of pulmonary dysfunction of individuals, for this reason spirometry method is of great value. Any disruption in the body's respiratory system will result in reducing the overall body performance and disturbing the oxygen supply to it (15).

Lack of physical activity or conversely, intensive physical activity in the long term, causes disorders in lung function, limits the flow of inhalation and exhalation and increase thickness of the respiratory tracts. Activity of respiratory organs would be faced with some problems, especially when you take part in intensive physical activity. It seems that athletes will experience restrictions in their lung volumes and capacities, particularly "dynamic capacity" during very intense physical activities and because of frequent and repeated inhalation of air into the respiratory tracts. Lungs need deeper inhalation and exhalation and faster air flow rate during very intense physical activity, and as a result of increased thickness and fibrosis of air ways, many restrictions are imposed on the function of the respiratory tract (13).

Some studies have shown that continuous physical activity can improve the function of respiratory system. On the other hand, physical activity is considered as a cause of bronchospasm, to the extent that high percentage of athletes with no 
history of asthma, experience bronchospasm during or after exercise and a percentage of these individuals are marked. The bronchospasm is seen even in many professional athletes (4). Exerciseinduced asthma (EIA) is considered as a temporary increase in the thickness of the airways in the lung and often occurred after long-term and intense exercise. Physical activity may be the only factor that triggers asthma especially in elite athletes with no symptom(s) of it. Exercise-induced bronchoconstriction (EIB) may be the more appropriate term that is independent of the physiological response caused by the disease (16) and it is difficult to say whether exercise acts as a developer or as an aggravating factor latent in asthma (17). Exercise-induced asthma prevalence was between $4 \%$ to $20 \%$ in the general population $(17,22)$. The prevalence of EIB in the athlete population varies from $11 \%$ to $55 \%(14,17)$.

Different studies were conducted on various kinds of exercises and the bronchospasms caused by them and they are divided into two categories, accordingly. The first category includes exercises that most likely cause bronchospasm. These exercises are the ones that can be performed in cold, dry air such as skiing and ice hockey, or exercises that require high volume ventilation, such as basketball and American football, cycling and endurance running. Second classification includes exercises that last for a short time like weightlifting and martial arts, wrestling, and exercises require no high physical intensity such as golf, volleyball and swimming (20). Game \& Bell (12) studied the effect of a competitive season on lung function and aerobic capacity on college hockey players. They measured the lung volume and $\mathrm{VO}_{2} \max$ in 40 ice hockey players before and after the season. The data showed that there was no significant change in Vo2max after the season. Also, forced vital capacity (FVC) and Forced Expiratory Volume in One Second (FEV1) was significantly decreased after the season. They concluded that a number of hockey players, due to cold weather and environmental space pollutants such as sulfur oxide experience airway narrowing (10). Unal \& Sahinkaya (24) studied prevalence of exercise-induced bronchospasm in professional athletes. The study was conducted on 126 elite athletes, including 85 football players, 25 karatekas, 11 swimmers and 5 wrestlers. Spirometric indices were measured in these groups before and after 10 minutes of exercise on a treadmill according to the Bruce Protocol .Some degree of bronchospasm was observed through changes in air flow and spirometry tests among athletes. It should be noted that $10 \%$ and $15 \%$ decrease in FEV1 or Forced Expiratory Flow From 25\% to 75\% (FEF 25-75\%), respectively, are signs of exercise-induced bronchospasm onset. There were reports on the $10 \%>$ decline in FEV1, 15\%> decline in FEF25-75 and $15 \%>$ decline in PEF in $11 \%(14), 14 \%$ (18) and $11 \%$ (14) of the athletes, respectively (25). On the other hand, some studies have shown contradictory results. For example, the results of short-term crosssectional spirometry study showed that, lung volumes of young athletes compared with nonathletes are not much different but spirometry tests have been done by adult endurance athletes with higher indices (11). Also Eizadi et al. (11) revealed that endurance training can make a difference in the spirometric performance of adult professional athletes. They showed that FEV1 was significantly increased during endurance training of 15 endurance runners but there was no change in FVC. In their study, Rubaie et al. (2013) examined the prevalence of airway obstruction in professional wrestlers, and came to the conclusion that following an exhaustive exercise session of Strand Test, spirometric indices showed the greatest decline at 5 and 15 mints (2). In another study, Parastesh et al. (1) examined the response of lung function indices to anaerobic activity in polluted environment and came to the conclusion that the anaerobic activity in polluted environment reduces lung function indices indicating that the polluted environment puts the athlete at a greater risk of exercise-induced asthma.

In athletes, endurance trainings increase cardiac output and receiving and consumption of oxygen by peripheral muscles. However, the lung tissue is less adapted with regular exercise and in endurance trainings; athletes can conduct ventilator endurance tests better than non-athletes. The difference between athletes and non-athletes in cross-sectional studies has been clearly shown (10). Accordingly, studying of ventilation system of athletes is invaluable, particularly to evaluate the impact of specific training exercises on pulmonary function and increased incidence of bronchospasm in athletes of different fields, particularly endurance sports in which underdevelopment and weakness of the respiratory system can be considered as limiting cause of such activities. Therefore, the goal of the present study is to compare the changes in intensive competitive exercise -induced respiratory tract congestion as well as the difference in respiratory volumes of the Islamic Republic of Iran's national rowing and kayak teams, and how much is the 
magnitude of competitive exercise-induced asthma in athletes and in which sports, these changes are higher?

\section{METHODS \& MATERIALS}

Twenty Iranian elite rowers and Kayak players took part in this study. All athletes were competing at national or international level and were in Iranian national team. All subjects were free from a history of pulmonary function impairment (excluding asthma) and free of respiratory tract infection for at least 4 weeks prior to testing. All volunteers who showed normal pulmonary function were included in the study. However, if the subject showed abnormal pulmonary function, he was excluded from the study. Subjects agreed to all testing requirements and procedures by giving his/her written consent prior to testing. None of the subjects had any experience in respiratory exercises prior to testing. The study protocol was approved by the Ethics Committee of University of Rajai. During a single visit to the laboratory, subjects underwent the following tests: anthropometric assessments (stature, weight and body composition), Body mass and height were assessed to the nearest $0.1 \mathrm{~kg}$ and $0.1 \mathrm{~cm}$, respectively. Body fat percentage was estimated using the three-site skinfold procedure according to standards with a Lafayette caliper (model 01127, USA). Maximal aerobic test was used to measure $\mathrm{VO}_{2}$ max, pulmonary function tests. Subjects were requested to refrain from exercise, alcohol and caffeine $24 \mathrm{~h}$ before testing. Subjects were asked to perform these tests during the competition phase of their specific sport season to ensure that all subjects had a reasonable level of fitness for their specific sport during their evaluation.

The athletes were already familiar with the 2000 meter special rowing ergometer test. All subjects attended two sessions (familiarization and test session) throughout the study; the athletes were already familiar with the $2000 \mathrm{~m}$ ergometer test, having performed it numerous times as part of training and competition. A Baseline 2,000-m rowing ergometer time trial (TT) was completed and spirometry test was done before and three times after that to reveal bronchospasm.

Environmental conditions in the laboratory were 40 to 49 percent humidity and temperatures were 19 to $24^{\circ} \mathrm{C}$. digital spirometer was used to obtain the indices and lung capacities. Since, the position of athlete at the time of performing the spirometry test has an important effect on results, so all athletes were tested in the same way. For this, all athletes were leaning on the chair and athletes tried to stay in an appropriate position to testing process. Also, procedure was fully explained before the test and how doing test was showed in practical manner and they repeated trails to completely being familiar, to measure the percentage change in the bronchospasm index following formula was used (18).

$\frac{\text { post test }- \text { pre test }}{\text { pre test }} \times 100=$ percentage change

Best way to recognize EIB is to detect changes in the airways after exercise test. Usually EIB becomes apparent 5 to 15 minutes after exercise, for this, respiratory function tests were done before, 1 , 15 and $30 \mathrm{~min}$ after the $2000 \mathrm{~m}$ ergometer time trail (25). $10 \%, 15 \%$ and $15 \%$ reduction in FEV1, PEF(peak expiratory flow) and FEF25-75, respectively, were signs of the onset of exercise bronchospasm (22), that in current study these indices (bronchospasm) was measured before and three times after $2000 \mathrm{~m}$ ergometer test $(8,18)$.

All values are expressed as means $\pm \mathrm{SD}$. Before parametric analyses were done, the normality of distribution of the data was assessed with Kolmogorov-Smirnov tests. A two-way (groups $\times$ time) analysis of variance (ANOVA) with repeated measures was conducted to determine the interaction and main effects. Where a significant main effect and/or interaction was observed, oneway ANOVA of pre-intervention to postintervention differences (absolute values) was applied to determine the source of significance. Effect size (ES) was determined and reported. When ANOVA revealed significant, Bonferroni method was used for post-hoc comparisons to times, and $t$ student to detecting between group significant differences. For all tests, $\mathrm{P}<0.05$ was considered as significant. All statistical tests were performed using SPSS software, version 16 .

\section{RESULTS}

Descriptive characteristics of the subjects are shown in Table 1. Table 2 shows changes in experimental variables and any likely differences related to time of measure (within group) and group. $2000 \mathrm{~m}$ time trail resulted in significant $(\mathrm{P}<0.05)$ decrease in all pre to post values (time variation) except rowers FVC ( $P>0.05)$. However, no significant differences indicated between the groups $(\mathrm{P}>0.05)$. This finding has appeared in Table 2. 
Table 1. General characteristics (Mean \pm SD) of subjects.

\begin{tabular}{lc}
\hline Variable & Mean \pm SD \\
\hline Age (years) & $23.03 \pm 2.11$ \\
Height $(\mathrm{cm})$ & $182.14 \pm 4.2$ \\
Weight $(\mathrm{kg})$ & $80.04 \pm 5.6$ \\
Body fat $(\%)$ & $11.3 \pm 1.5$ \\
VO $^{2}$ max $(\mathrm{ml} / \mathrm{kg} / \mathrm{min})$ & $62.2 \pm 2.4$ \\
\hline
\end{tabular}

Table 2. Respiratory variables indices in both groups before and three times after 200m special ergometer test.

\begin{tabular}{|c|c|c|c|c|c|c|c|}
\hline Variable & Group & Time of test & $\begin{array}{c}\text { Value } \\
\text { (means } \pm \\
\text { SD) }\end{array}$ & $\begin{array}{l}\text { Percentag } \\
\text { e change }\end{array}$ & $\mathrm{F}$ & $\begin{array}{l}\text { P (Within } \\
\text { group) }\end{array}$ & $\begin{array}{l}\mathrm{P} \text { (Between } \\
\text { group) }\end{array}$ \\
\hline \multirow[t]{8}{*}{ FVC } & \multirow[t]{4}{*}{ Kayak } & Pre test & $82.72 \pm 0.5$ & & \multirow[t]{4}{*}{12.62} & \multirow[t]{4}{*}{$0.001^{*}$} & \multirow[t]{8}{*}{0.53} \\
\hline & & $\begin{array}{l}\text { Immediately Post } \\
\text { test }\end{array}$ & $45.01 \pm 0.5$ & $1 . \% 14$ & & & \\
\hline & & 5 min after test & 40.370 .5 & $1 . \% 6$ & & & \\
\hline & & $30 \mathrm{~min}$ after test & $83.68 \pm 0.5$ & $070 . \%$ & & & \\
\hline & \multirow[t]{4}{*}{ Rowers } & Pre test & $7.34 \pm 0.5$ & & \multirow[t]{4}{*}{0.885} & \multirow[t]{4}{*}{0.441} & \\
\hline & & Post test & $65.16 \pm 0.5$ & $1 . \% 7$ & & & \\
\hline & & 5 min after test & $17.24 \pm 0.5$ & $3 . \% 2$ & & & \\
\hline & & $30 \mathrm{~min}$ after test & $70.28 \pm 0.5$ & $1 . \% 1$ & & & \\
\hline \multirow{8}{*}{ FEV1 } & \multirow[t]{4}{*}{ Kayak } & Pre test & $12.29 \pm 0.5$ & & \multirow[t]{4}{*}{10.32} & \multirow{4}{*}{$0.001^{*}$} & \multirow[t]{8}{*}{0.138} \\
\hline & & Post test & $13.91 \pm 0.4$ & $1 . \% 7$ & & & \\
\hline & & 5 min after test & $12 . \pm 012.5$ & $2 . \% 3$ & & & \\
\hline & & 30 min after test & $11.28 \pm 0.5$ & $18 . \% 0$ & & & \\
\hline & \multirow[t]{4}{*}{ Rowers } & Pre test & $13.5 \pm 0$ & & \multirow[t]{4}{*}{5.64} & \multirow[t]{4}{*}{$0.028^{*}$} & \\
\hline & & Post test & $15.69 \pm 0.4$ & $2 . \% 6$ & & & \\
\hline & & 5 min after test & $13.85 \pm 0.4$ & $\% 3$ & & & \\
\hline & & 30 min after test & $14.96 \pm 0.4$ & $8 . \% 0$ & & & \\
\hline \multirow[t]{8}{*}{ FEF25.75 } & \multirow[t]{4}{*}{ Kayak } & Pre test & $92.72 \pm 0.5$ & & \multirow[t]{4}{*}{13.51} & \multirow[t]{4}{*}{$0.002^{*}$} & \multirow[t]{4}{*}{0.75} \\
\hline & & Post test & $71.25 \pm 0.5$ & $2 . \% 8$ & & & \\
\hline & & 5 min after test & $83.53 \pm 0.5$ & $3 . \% 3$ & & & \\
\hline & & $30 \mathrm{~min}$ after test & $94.66 \pm 0.5$ & $\% 1$ & & & \\
\hline & \multirow[t]{4}{*}{ Rowers } & Pre test & $63.86 \pm 0.5$ & & \multirow[t]{4}{*}{9.95} & \multirow[t]{4}{*}{$0.009^{*}$} & \\
\hline & & Post test & $68.35 \pm 0.5$ & $7 . \% 8$ & & & \\
\hline & & 5 min after test & $62.60 \pm 0.5$ & $4 . \% 4$ & & & \\
\hline & & $30 \mathrm{~min}$ after test & $62.78 \pm 0.5$ & $3 . \% 1$ & & & \\
\hline \multirow[t]{8}{*}{ PEF } & \multirow[t]{4}{*}{ Kayak } & Pre test & $35.56 \pm 0.9$ & & \multirow[t]{4}{*}{27.82} & \multirow[t]{4}{*}{$0.001^{*}$} & \multirow[t]{8}{*}{0.275} \\
\hline & & Post test & $34 . \pm 069.8$ & $1 . \% 9$ & & & \\
\hline & & $5 \mathrm{~min}$ after test & $30.43 \pm 08$ & $8 . \% 11$ & & & \\
\hline & & $30 \mathrm{~min}$ after test & $35.44 \pm 09$ & $2 . \% 1$ & & & \\
\hline & Rowers & Pre test & $38.89 \pm 0.8$ & & 13.67 & $0.001^{*}$ & \\
\hline & & Post test & $39.29 \pm 0.8$ & $7 . \% 6$ & & & \\
\hline & & 5 min after test & $33.05 \pm 0.8$ & $4 . \% 9$ & & & \\
\hline & & 30 min after test & $39.65 \pm 08$ & $6 . \% 2$ & & & \\
\hline
\end{tabular}

* Significant difference within groups.

\section{DISCUSSION}

Various fields of boating are associated with periodic intense activities and yet different physical periods. Athletes of these fields require maximal oxygen uptake and a body with high physical fitness (15). During this exercise, different body systems will be involved to varying degrees. One of these systems is the respiratory system and during this exercise high ventilation volume is required. The results of our study showed that changes in respiratory indices between these two fields are not significant and all indices indicating significant changes in kayak $(p<0.05)$ but in rowing, the only variable that shows no significant change was Forced Vital Capacity (FVC). But the percentage of changes did not show any signs of exercise-induced asthma $(<15 \%)$.

Smith et al. (23) in a study entitled prevalence of airway obstruction in Irish athletes, examined restriction and obstruction of airways and bronchospasm and exercise-induced asthma among Ireland's university athletes. They classified athletes 
into five groups: field sports, indoor sports, endurance sports, martial arts and swimming. Varying degrees of bronchospasm was reported and the highest rate was observed in the swimming group with 9.6 percent decline in their FEV1. In Smith's opinion, the greatest reduction in pulmonary values occurred after performing intense exercises in cold environments (23). Uçok et al. (24) in a study in Erzurum, Turkey, examined prevalence of exercise-induced bronchospasm in long-distance runners who trained in cold weather conditions. 20 male long distance runners who trained in cold weather conditions and 19 inactive men were selected for comparison. None of the participants had a history of asthma or allergies. Bronchospasm was defined as reduction of $10 \%>$ in FEV1 or $15 \%>$ in FEF25-75 or reduction rate of $25 \%>$ in PEFR. Also, spirometry parameters were measured before and after exercise. Bronchospasm was observed among 7 athlete runners, and an individual from inactive group (24). Ratdl \& Jackson (2002), in their research, reported prevalence of exercise-induced bronchospasm among endurance runners, sprint runners and among athletes participating in the Winter Olympics 1998 as $17 \%, 8 \%$ and $23 \%$, respectively (22). Pohjantähti et al. (21) examined exercise-induced bronchospasm among the top Finnish skiers. There were 20 skiers in this study. After measuring spirometry parameters, it became clear that $35 \%$ of skiers suffered from some degrees of exercise-induced bronchospasm. Most of the reduction among pulmonary parameters was related to a decrease in peak expiratory flow (PEF) It seems that cold condition plays important role in the prevalence of exercise-induced bronchospasm among skiers and due to the frequent inhalation of cold air and a lack of time to be wetted, an obstruction will be made in the respiratory tract, especially in the small airways which leads to a decline in the lung function indices (21). In Randall, Purjantaty and Yuk studies, incidence rate of bronchospasm in cold winter conditions has been examined and it was shown that risk of bronchospasm was increased as a result of cold weather, but in our study, due to moderate temperature, incidence rate of bronchospasm was less than study of Randall, Purjantaty and Yuk. Bonini et al. (7), in a study, examined lung performance tests for some degree of exerciseinduced asthma or respiratory allergies in elite athletes. 98 athletes were studied at the 2004 Olympics. The results of spirometry test evaluation showed that the prevalence of asthma among athletes was $20.4 \%$. In a study on professional cyclists, Medelli et al. (14) evaluated lung performance tests. 25 professional cyclists were selected with the age range of 27.9. Using sports and medical history questionnaire, the presence or absence of asthma was evaluated. Lung indices of FEV1, FEV1 / FVC and FEF25-75 were measured and $52 \%$ of the samples showed signs of upper airway obstruction. Barkard et al. (2007) conducted a study to investigate the indices of respiratory diseases among Polish rowers. 79-men from national team and Olympic rowers were selected in this study. Using spirometer, lung function parameters were measured before and after a rowing championship. Initially the obtained values of all measured indices were higher than those predicted by the device. Comparing the indices before and after the contest, also no significant differences were obtained among them. They believed that there were no respiratory restrictions, such as asthma, airway obstruction or exercise-induced bronchospasm in this group (7). According to the obtained results of this study and after comparing them with results of Barkard's study, it may be noted that the reason for consistency of the results of the two studies is due to the type of subjects, training systems, activity protocols, certain anthropometric athletes and their aerobic fitness, which were not observed in both studies on exercise-induced asthma. After comparing kayak and rowing and as mentioned above, all indices in kayak showed significant changes ( $p<0.05$ ) but, in rowing, the only variable that shows no significant change was the Forced Vital Capacity. And percentage of decreasing changes in kayak was more than rowing likely due to the activity level and movement patterns of these fields. As in kayak legs are also involved, so level of physical fitness of the athletes as well as the muscles involvement in this field is higher which contributes to the increased readiness of the athletes. Studying of ventilation system of athletes is invaluable, particularly evaluation of the specific training exercises impact on pulmonary functions in athletes of different fields, particularly intense and periodic sports in which underdevelopment and weakness of the respiratory system can be considered as limiting cause of such activities. Ventilation of maximum, endurance and periodic activities will be increased by improvement of maximal oxygen intake. It is physiologically justified because any increase in aerobic capacity requires more oxygen intake and in proportion with it, more carbon dioxide is produced that should be excreted from pulmonary ventilation 
(5). Despite numerous conducted studies, the fact that sport and type of physical activity is the cause of bronchospasm or exercise predisposes respiratory system to the impact of driving factors is still in question. It is therefore clear that individuals with a history of breathing problems such as asthma will not take part in this type of sport or they are not chosen as a member of sports teams of the field. Consequently, intense and pathological changes in professional athletes in this field are not expected. On the other hand, many athletes may experience symptoms that may not pay attention to them or visit medical clinic for different reasons including low intensity of the symptoms and compromising their athletic position. However, conducting repeated spirometries reduce the risk of error and increase the likelihood of detecting spasm. However, in cases where the diagnosis cannot be achieved with this method, using histamine stimulation test with methacholine after exercise, better demonstrates changes in the ventilation system during exercise (3). For example, in the study of Wheeler et al., although none of the athletes had a history of asthma, the result of methacholine stimulatory test was positive in $25 \%$ of the subjects (3). Using mask as a non-pharmacological strategy is recommended to reduce the severity of symptoms of EIB during activity in order to wet the air of a cold and dry environment (19). But according to the results of this research, it can be concluded that the rowing and kayak athletes are less susceptible to exercise-induced asthma because of the high aerobic and physical fitness.

\section{REFERENCES}

1. Prastesh M, Shavandi N, Saremi A, Akbar G, Alibakhshi I. Response some lung function indices to aerobic exercise in polluted air service in young men. Sports Science Research. :2010; 8: 65-74

2. Rubaie MA, Ghanbarzadeh M, Habibi AH, Mrshyan SH. The prevalence of airway obstruction resulting from the exercise of professional wrestlers Greco. Motor sport magazine and Life Sciences. 2013; 4(2): 35-44

3. Farhoudi A, Zeyaii V, Halabchi F, Ahmadinejad Z. Sports asthma is and how we deal with patients with asthma exercise. The Journal of the Medical Council, 2004; 22(1):4254.

4. Ziaee V, Ahmadinejad Z, Farah A, Movahhedi M, Mansoornia MA. Compared the pulmonary function tests before and after the sport of basketball in professional and semi-professional basketball. Journal of Basic Medical Sciences, 2006; 9(3): 172-177.

5. Abdolhamid Tehrani M. The effect of Aerobic Exercise on Pulmonary Indexes in Obese Women from Iran. EuroasianGastroenterol, 2012; 2(1): 28-29.
6. Aliverti A, Dellaca R, Lotti P, Bertini S, Duranti R, Scano G, Heyman J, Lo Mauro A, Pedotti A, Macklem P. Influence of expiratory flow-limitation during exercise on systemic oxygen delivery in humans. European Journal of Applied Physiology, 2005; 95(2): 229-242.

7. Bonini M, Lapucci G, Petrelli G, Todaro A, Pamich T, Rasi G, Bonini S. Predictive value of allergy and pulmonary function tests for the diagnosis of asthma in elite athletes. Allergy, 2007; 62(10): 1166-1170.

8. Bruce CR, Anderson ME, Fraser SF, Stepto NK, Klein R, Hopkins WG, Hawley JA. Enhancement of 2000-m rowing performance after caffeine ingestion. Med Sci Sports Exerc, 2000; 32(11): 1958-1963.

9. Burkhard-Jagodzińska K, Zdanowicz R, Kozera J, Borkowski L, Sitkowski D, Karpiłowski B. Verification of the basic valuesof respiratory indices due to Polish kayakers. Biol Sport, 2007; 24(1): 31-46.

10. Courteix D, Obert P, Lecoq AM, Guenon P, Koch G. Effect of intensive swimming training on lung volumes, airway resistance and on the maximal expiratory flow-volume relationship in prepubertal girls. Eur J Appl Physiol Occup Physiol, 1997; 76 (3): 264- 9.

11. Eizadi M, Seyed Hoseini M.A, Khorshidi D, Dooaly H . Respiratory function does not affect by a single bout cycling in obese men. J Bio \& Env Sci, 2011.

12. Game AB, Bell GJ. The effect of a competitive season and environmental factors on pulmonary function and aerobic power in varsity hockey players. Applied Physiology, Nutrition, and Metabolism, 2006; 31(2): 95-100.

13. Hall JE. Guyton AC. Textbook of Medical Physiology. Elsevier Health Sciences, 2010.

14. Medelli J, Lounana J, Messan F, Menuet J, Petitjean M. Testing of pulmonary function in a professional cycling team. Journal of Sports Medicine and Physical Fitness, 2006; 46(2): 298.

15. Hoffman JR. Physiology of Basketball. In: McKeag G, (ed.), Basketball Malden, Blackwell Science, 2003; 12-24.

16. Holzer K, Douglass JA. Exercise induced bronchoconstriction in elite athletes: measuring the fall. Thorax, 2006; 61(2): 94-96.

17. Messan F, Marqueste T, Akplogan B, Decherchi P, Grélot L. Exercise-Induced Bronchospasm Diagnosis in Sportsmen and Sedentary. ISRN Pulmonology, 2012; 1-8.

18. Mughal SA, Mughal MA, Khan Zardari M, Ahmed ST. A study of exercise-induced bronchospasm in urban and rural school children of sindh. Pak J Physiol, 2008; 4(2): 209-216.

19. Parsons JP, Mastronarde JG. Exercise-induced bronchoconstriction in athletes. CHEST Journal, 2005; 128(6): 3966-3974.

20. Parsons JP, Mastronarde JG. Exercise-induced asthma. Current Opinion in Pulmonary Medicine, 2009; 15(1): 25-28.

21. Pohjantähti H, Laitinen J, Parkkari J. Exercise-induced bronchospasm among healthy elite cross country skiers and non-athletic students. Scandinavian Journal of Medicine \& Science in Sports, 2005; 15(5): 324-328.

22. Rundell KW, Jenkinson DM. Exercise-induced bronchospasm in the elite athlete. Sports Medicine, 2002; 32(9): 583-600. 
23. Smith E, Mahony N, Donne B, O'Brien M. "Prevalence of obstructive airflow limitation in Irish collegiate athletes. Irish Journal of Medical Science, 2003; 171(4): 202-205.

24. Uçok K, Dane Ş, Gökbel H, Akar S. Prevalence of exerciseinduced bronchospasm in longdistance runners trained in cold weather. Lung, 2004; 182(5): 265-270.
25. Unal M, Sahinkaya $T$. The prevalance of exercise induced bronchoconstriction in elite athletes Journal of Sports Science and Medicine, 2004; 3: 57-59. 